\title{
Effect Professional Practical Model on Nurse Manager's Work Satisfaction
}

\author{
Hanaa Mohamed Ahmed ${ }^{1}$ \& Karima Hosny Abdelhafez ${ }^{2}$ \\ ${ }^{1 .}$ Lecturer in Nursing Administration Department, Faculty of Nursing, Assuit University, Egypt. \\ 2. Assistant Professor in Nursing Administration Department, Faculty of Nursing - Assuit University, Egypt.
}

\begin{abstract}
:
Background: Professional practice model is a reasonable and viable alternative to the traditional nursing practice models used in many hospitals. Aim: assess the effect of professional practical model on Nurse Manager's work satisfaction. Study design: A descriptive correlational design. Setting: at different Hospitals at Assiut University. Subject: Convenient sample of Nurse Manager's work at Assiut University Hospitals No. $=(168)$ at all units. Methods: The data were collected using: Self-administered questionnaire including: personal data sheet, professional practical model questionnaire \& work satisfaction scale nurse (WSSN). Results: The highest mean score of items of professional practical model in El Rajhe hospital in the study subject Professional development, Shared governance, Primary care team, Quality outcomes, Transformational leadership and Stewardship. While the highest mean score of items Teamwork in Al Orman Hospital, followed by in El Rajhe hospital) Conclusion: and finally in main hospital, this resulted statistically significance differences among hospitals in the study in items Stewardship, Teamwork, Quality outcomes and Primary care team., There was a highly positive correlation between professional practical model and work satisfaction items. Recommendation: Encourage the nurse manager to Participate in workshop about Professional practical model to increase their commitment toward goal achievement.
\end{abstract}

\section{Keywords: Professional practical model, Nurse Managers \& Work satisfaction}

\section{Introduction:}

Professional practical model has attracted the attention of nursing over the last decade in response to maintaining nursing job satisfaction and quality care. Professional practical model, defined as allow nurses to have an active role in the decision making process relies on individual autonomy, authority and control (Kennerly, 2000). On the other hand Hawkins, et al (2011) reported that, the Professional Practice Model is a visual portrayal of the qualities, authoritative constructions, and cycles that give a binding together structure to the act of nursing. It guarantees consistency in the conveyance of nursing care, and characterizes for all enrolled attendants authority, self-rule and responsibility as they care for patients and families locally, our state and world. Authority: The acknowledgment and utilization of our privileges and obligation to utilize our nursing information, abilities, and decisions, to give top notch results to our patients, self-governance: the creation of free nursing choices about the best nursing practices to carry out to give protected, excellent results for our patients, responsibility: The acknowledgment of duty regarding our activities, decisions, and the subsequent results (Main Line Health, 2020).

Moreover Meehan, (2020) defined the Professional practical model as a "framework (structure, process, and values) that supports nurse authority over the conveyance of nursing care and the climate in which care is conveyed". An expert practice model is a framework or system that upholds proficient medical attendants in their regular practice. This model backings our faith in the significance of predominant patient consideration dependent on organizations among nursing and different clinicians, patients, families and the local area.

Slatyer et al., (2016) recommend that nursing's reception of health care authoritative values guarantees that nursing is completely converged with the organizational culture where attendants are utilized. Nonetheless, except if nurses are really overseeing a health care organizational culture, there is no affirmation that nursing esteems will be perceived and followed up on. The shortage of nursing has been connected to general occupational satisfaction and explicitly agreeable to the professional practice climate. Drives to build maintenance and enrollment and reduction turnover have been connected to work satisfaction among nurses. One of the early yet suffering objectives of professional practical model was to improve the workplace, fulfillment, and maintenance of nurses. (Karen, et al 2012). Given the vital job that nurses play in deciding the proficiency, adequacy and sustainability of health care system, it is critical to comprehend what inspires them and the degree to which the association and other relevant factors satisfy them.

Buchan, (2018) A Professional Practice Model is a schematic that represents our $\mathrm{v}$ for nursing practice. 
It addresses a system for nursing greatness and is an extraordinary portrayal of the multitude of key parts of nursing practice. It addresses nursing practice across each setting: inpatient, outpatient, and interventional care scenes (Stanford Health Care, 2000). Stewardship is an ethic that typifies the capable arranging and the board of assets. The ideas of stewardship can be applied to the climate and nature, financial aspects, wellbeing, property, data, religious philosophy, and social assets and so forth the work of overseeing or dealing with something, like an association or property. Foundational disappointments can't be attributed to the stewardship of an ideological group (Wikipedia, 2019).

Teamwork is the collective exertion of a gathering to accomplish a shared objective or to finish an undertaking in the best and effective manner. This idea is seen inside the more noteworthy system of a team, which is a gathering of reliance people who cooperates towards a shared objective. Teams should have the option to use assets to be gainful (for example battlegrounds or meeting spaces, booked occasions for arranging, direction from mentors or directors, support from the organization, and so on) (Michael 2012). Fundamental necessities for successful collaboration are a satisfactory team size. The setting is significant, and team sizes can shift contingent on the goal (Roger, 2015). Fundamental group elements include: Open correspondence to keep away from clashes, Effective coordination to stay away from disarray and the violating of limits, proficient participation to play out the assignments in an opportune way and produce the necessary outcomes, particularly as responsibility sharing, High degrees of reliance to keep up undeniable degrees of trust, hazard taking, and execution (Wikipedia, 2019).

Nurses are more professional group giving consideration in medical clinics, however quick turnover has been a huge issue. Cutting edge innovation and abbreviated lengths of stay, compounded by unbendable planning and high patient acuities, add to diminished work satisfaction (Hazel.et al 2006). Furthermore, dissatisfaction in nursing can result from lack of respect by colleagues, inadequate opportunity for growth and promotion and lack of independence and freedom in patient care situations. Autonomy is a significant determinant of nurses' job satisfaction and turnover. Staff nurses saw autonomy (self-governance) as the main determinant of work satisfaction and choice to remain or leave the health care organization. (Krajewski, 2012).

Setting Goals institution (2019), Referenced that central issues to improve work satisfaction something that individuals concern them with as they start the vocation is work satisfaction. Nowadays' kin wind up exchanging continually between occupations. It is frequently in these events when the subject of accomplishing job satisfaction comes in to play. Being cheerful in vocation relies upon and explicit requirements and assumptions. It's dependent upon each person to acknowledge what might truly make them cheerful and where would they be able to discover the satisfaction they want (Susan, 2011) Employee satisfaction is the wording used to depict whether representatives are glad and satisfied and satisfying their cravings and requirements at work worker satisfaction is a factor in representative inspiration, worker objective accomplishment, and positive representative resolve in the work environment.

Susan, (2011) Mentioned that, Elements adding to worker fulfillment incorporate approaching representatives with deference, giving customary representative acknowledgment, engaging representatives, offering above association normal advantages and pay, giving worker advantages and association exercises, and positive administration inside a triumph system of objectives, estimations, and assumptions. Representative fulfillment is frequently estimated by the board, comprehension of mission and vision, strengthening, teamwork, communication, and collaborator connection.

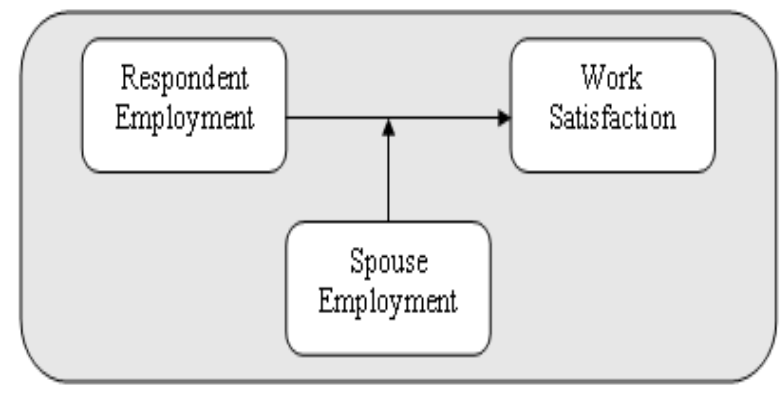

Employment-Work Satisfaction Framework

Significance of the study: while the researcher reviewed of the literatures found that there were internationally studies published in professional articles and journals, the first one titled by "Nurses' perceptions of the impact of a renal nursing professional practice model on nursing outcomes, characteristics of practice environments and empowerment. done by (Karen, 2017). the second one titled by" Professional Practical Model and its effect work satisfaction " made by (Wikibedia, 2019) and lastly the third one titled by" Nurses perceptions of their professional practice environment in relation to job satisfaction: a review of quantitative studies." 
studied by (Anastasios, et al 2019) and there is No national studies dealing with the professional practical model and it was seen that there were no researches done in Upper Egypt about professional practical model, so that the researcher likes to study the perception of Nurse Managers about the professional practical model and effects on Nurse Manager's satisfaction at Assuit University Hospitals.

Aim of the study: The current study aim to: assess the effect of professional practical model on Nurse Manager's work satisfaction. at Assiut University Hospital.

The research hypotheses: positive correlation among professional practical model items and Positive correlation between professional practical model and work satisfaction.

\section{Methods:}

A descriptive correlational study design was conducted at Assuit University Hospitals (Main Hospital - El Rajhe Hospital and Al Orman Hospital). Convenient sample of Nurse Manager's work at Assiut University Hospitals No. $=(168)$ at all units, classified as following: Main Hospital No. = (120), El Rajhe Hospital No $=(32)$, and Al Orman Hospital No. = (16).

Data collection tools: The study tools included the following: (I) Personal \& job characteristics sheet: Includes information about Nurse Managers such as gender, age, educational level, unit, years of experience in the hospital. (II) Professional practical model Questionnaire: It developed by Megginson, L (2017), consisted of 26 items structured in seven categories: Stewardship (two items), Teamwork (two items), Primary care team (Four items), Professional development (Four items), Quality outcomes (Three items), Shared governance (Seven items), and transformational leadership (Four items). It consists of 26 items, the responding of all items was (1) for Yes and (0) for No. (III) Work Satisfaction Scale Nurse (WSSN): It developed by Ahmed,(2013) it consisted of 32 items the responding scoring system was measured by 3 points likert scale ranging from (1) for dissatisfied, (2) for natural and (3) for satisfied.

\section{Study procedures:}

After inspecting the accessible writings concerning the subject of the examination, Translation of the tools from English to Arabic was finished. It required around four months from June to September 2019. Official authorization acquired to gather information from heads of the Assiut University Hospitals (Main Hospital, El Rajhe Hospital, and Al Orman Hospital), official consent got to gather essential information from general overseer of nursing organization office at Assiut University Hospitals.
Faced validity was done to assure accurate comprehension of the study tool. The data was collected by the researcher through structured interviewing with Nurse Managers. The researcher had explained the questionnaire to each one. The time taking with each participant was about twenty minutes at mourning shift. This phase took about three months from October to December 2019. That was done through a jury (expert opinions) composed of 3 professors and 2 assistant professors from the Nursing Administration and Community Health Nursing Departments, Faculty of Nursing, Assuit University. Also, content validity was checked and analyzed using confirmatory factor analysis test to assure (importance, clearness, and accountability of each items of the study tool) and its result was $\mathbf{Z} \mathbf{1 . 8}$ for all items of the study tool. A pilot study was done to survey tools clarity and applicability. Moreover, to recognize issues that might be experienced during the actual data collection. It applied on sixteen Nurse Managers from various units of the medical clinics remembered for the investigation test chose from Assiut University hospitals.

Data collected from the pilot study were analyzed to test consistency of study tool using Cronbach's Alpha Coefficient test. The result was $\alpha \geq 0.86$ for each item of the tool items. The Nurse Managers included in the pilot study were Included from the present study. Study proposal take agreement from the ethical committee in the faculty of nursing at Assiut University, Oral consent was taken from the participatory Nurse Managers in the present study.

Data entry and analysis were done using SPSS version 20.program statistical software package for social sciences. Data were presented using descriptive statistics in the form of frequencies and percentages also mean and standard deviation were also calculated. For relation to identify effects of professional practical model on work satisfaction and correlation between variables in professional practical model scale (Pearson correlation) and (ANOVA test) were used, statistical significant was considered at $\mathrm{P}$ - value $\leq$ 0.05 . 


\section{Results:}

Table (1): Distribution of Personal \& job characteristics of the studied Nurse Managers,

\begin{tabular}{|c|c|c|c|c|c|c|c|c|}
\hline \multirow[t]{2}{*}{$\begin{array}{l}\text { Items of Personal\& } \\
\text { job characteristics }\end{array}$} & \multicolumn{2}{|c|}{$\begin{array}{c}\text { Main } \\
\text { Hospital } \\
(n=120)\end{array}$} & \multicolumn{2}{|c|}{$\begin{array}{r}\text { El Rajhe } \\
\text { Hospital } \\
(n=32)\end{array}$} & \multicolumn{2}{|c|}{$\begin{array}{c}\text { Al Orman } \\
\text { Hospital } \\
(n=16)\end{array}$} & \multicolumn{2}{|c|}{$\begin{array}{c}\text { Total } \\
(n=168)\end{array}$} \\
\hline & No. & $\%$ & No. & $\%$ & No. & $\%$ & No. & $\%$ \\
\hline \multicolumn{9}{|l|}{ Age: (years) } \\
\hline$<35$ & 59 & 49.2 & 22 & 68.7 & 5 & 31.2 & 86 & 51.1 \\
\hline $35-<40$ & 34 & 28.3 & 7 & 21.9 & 3 & 18.8 & 44 & 26.1 \\
\hline $40-<45$ & 13 & 10.8 & 3 & 9.4 & 3 & 18.8 & 19 & 11.3 \\
\hline $45-<50$ & 6 & 5 & 0 & 0 & 1 & 6.2 & 7 & 4.1 \\
\hline $50-\geq 50$ & 8 & 6.7 & 0 & 0.0 & 4 & 25 & 12 & 7.4 \\
\hline \multicolumn{9}{|l|}{ Sex: } \\
\hline Male & 7 & 5.8 & 0 & 0 & 0 & 0 & 7 & 4.2 \\
\hline Female & 113 & 94.2 & 32 & 100 & 16 & 100 & 161 & 95.8 \\
\hline \multicolumn{9}{|l|}{ Level of education: } \\
\hline Bachelor degree & 88 & 73.33 & 32 & 100.0 & 4 & 25.0 & 124 & 73.8 \\
\hline Master degree & 23 & 19.16 & 0 & 0.0 & 11 & 68.8 & 34 & 20.27 \\
\hline Doctoral degree & 9 & 7.5 & 0 & 0.0 & 1 & 6.2 & 10 & 5.95 \\
\hline \multicolumn{9}{|l|}{ Marital status: } \\
\hline Single & 22 & 18.3 & 4 & 12.5 & 2 & 12.5 & 28 & 16.7 \\
\hline Married & 94 & 78.3 & 27 & 84.4 & 14 & 87.5 & 135 & 80.4 \\
\hline Divorced & 2 & 1.7 & 1 & 3.1 & 0 & 0 & 3 & 1.8 \\
\hline Widow & 2 & 1.7 & 0 & 0 & 0 & 0 & 2 & 1.2 \\
\hline \multicolumn{9}{|l|}{ Years of experience: } \\
\hline$<5$ & 14 & 11.7 & 6 & 18.8 & 3 & 18.75 & 23 & 13.7 \\
\hline $5-<10$ & 38 & 31.7 & 18 & 56.3 & 0 & 0 & 56 & 33.4 \\
\hline $10-<15$ & 28 & 23.3 & 5 & 15.6 & 3 & 18.75 & 36 & 21.4 \\
\hline $15-<20$ & 16 & 13.3 & 1 & 3.1 & 2 & 12.5 & 19 & 11.3 \\
\hline$\geq 20$ & 24 & 20 & 2 & 6.2 & 8 & 50 & 34 & 20.25 \\
\hline
\end{tabular}

Table (2): Scores of professional practical model items as perceived by the studied Nurse Managers

\begin{tabular}{|c|c|c|c|c|}
\hline \multirow[t]{2}{*}{ Professional practical model items } & $\begin{array}{c}\text { Main } \\
\text { Hospital } \\
(n=120) \\
\end{array}$ & $\begin{array}{c}\text { El Rajhe } \\
\text { Hospital } \\
(\mathrm{n}=32) \\
\end{array}$ & $\begin{array}{c}\text { Al Orman } \\
\text { Hospital } \\
(n=16)\end{array}$ & \multirow[t]{2}{*}{ P-Value } \\
\hline & Mean \pm SD & Mean \pm SD & Mean \pm SD & \\
\hline Stewardship. & $0.90 \pm 0.77$ & $1.56 \pm 0.62$ & $1.31 \pm 0.70$ & $0.000 *$ \\
\hline Teamwork. & $0.35 \pm 0.60$ & $0.97 \pm 0.82$ & $1.00 \pm 0.73$ & $0.000 *$ \\
\hline Primary care team. & $1.58 \pm 1.13$ & $2.34 \pm 1.29$ & $1.44 \pm 1.31$ & 0.004* \\
\hline Professional development. & $2.69 \pm 1.24$ & $3.06 \pm 0.84$ & $2.50 \pm 1.03$ & 0.188 \\
\hline Quality outcomes. & $1.32 \pm 1.06$ & $2.19 \pm 1.00$ & $1.63 \pm 0.96$ & $0.000 *$ \\
\hline Shared governance. & $1.95 \pm 1.74$ & $2.84 \pm 2.05$ & $2.25 \pm 1.95$ & 0.050 \\
\hline Transformational leadership. & $1.78 \pm 1.21$ & $2.03 \pm 0.86$ & $1.81 \pm 1.17$ & 0.555 \\
\hline
\end{tabular}


Table (3): Scores of Nurse Managers satisfaction regarding items of professional practical model

\begin{tabular}{|c|c|c|c|c|c|c|c|c|c|c|c|c|}
\hline \multirow{3}{*}{$\begin{array}{c}\text { Professional } \\
\text { practical model } \\
\text { Items }\end{array}$} & \multicolumn{4}{|c|}{$\begin{array}{c}\text { Main Hospital } \\
(n=120)\end{array}$} & \multicolumn{4}{|c|}{$\begin{array}{c}\text { EI Rajhe Hospital } \\
(n=32)\end{array}$} & \multicolumn{4}{|c|}{$\begin{array}{c}\text { Al Orman Hospital } \\
(n=16)\end{array}$} \\
\hline & Satisfy & Undecid & Dissatisfy & $\mathbf{P}-\mathbf{v}$ & Satisfy & Undecid & Dissatisfy & $\mathbf{P}-\mathrm{v}$ & Satisfy & Undecid & Dissatisfy & $\mathbf{P}-\mathrm{v}$ \\
\hline & Mean \pm SD & Mean \pm SD & Mean \pm SD & & Mean \pm SD & Mean \pm SD & Mean \pm SD & & Mean \pm SD & Mean \pm SD & Mean \pm SD & \\
\hline Stewardship. & $1.50 \pm 0.53$ & $1.02 \pm 0.75$ & $0.22 \pm 0.42$ & $0.000 *$ & $1.33 \pm 1.15$ & $1.50 \pm 0.59$ & $2.00 \pm 0.00$ & 0.211 & $1.75 \pm 0.50$ & $1.40 \pm 0.52$ & $0.00 \pm 0.00$ & $0.004^{*}$ \\
\hline Teamwork. & $1.25 \pm 0.46$ & $0.36 \pm 0.61$ & $0.00 \pm 0.00$ & $0.000 *$ & $1.33 \pm 0.58$ & $0.88 \pm 0.80$ & $1.20 \pm 1.10$ & 0.538 & $1.25 \pm 0.50$ & $1.00 \pm 0.82$ & $0.50 \pm 0.71$ & 0.527 \\
\hline Primary care team. & $1.63 \pm 0.74$ & $1.80 \pm 1.15$ & $0.7 \pm 0.69$ & $0.000 *$ & $3.67 \pm 0.58$ & $2.13 \pm 1.36$ & $2.60 \pm 0.55$ & 0.130 & $2.00 \pm 1.41$ & $1.30 \pm 1.34$ & $1.00 \pm 1.41$ & 0.620 \\
\hline $\begin{array}{l}\text { Professional } \\
\text { development. }\end{array}$ & $2.25 \pm 1.39$ & $2.64 \pm 1.19$ & $3.04 \pm 1.36$ & 0.224 & $2.67 \pm 0.58$ & $3.21 \pm 0.88$ & $2.60 \pm 0.55$ & 0.240 & $2.50 \pm 1.29$ & $2.40 \pm 0.97$ & $3.00 \pm 1.41$ & 0.780 \\
\hline Quality outcomes. & $2.00 \pm 0.93$ & $1.46 \pm 1.06$ & $0.52 \pm 0.67$ & $0.000 *$ & $3.00 \pm 0.00$ & $1.92 \pm 1.02$ & $3.00 \pm 0.00$ & 0.023 & $2.25 \pm 0.96$ & $1.30 \pm 0.95$ & $2.00 \pm 0.00$ & 0.214 \\
\hline Shared governance. & $2.38 \pm 1.41$ & $2.25 \pm 1.75$ & $0.65 \pm 1.15$ & $0.000 *$ & $5.00 \pm 1.73$ & $2.92 \pm 2.00$ & $1.20 \pm 1.10$ & 0.032 & $3.00 \pm 1.63$ & $2.10 \pm 2.13$ & $1.50 \pm 2.12$ & 0.654 \\
\hline $\begin{array}{l}\text { Transformational } \\
\text { leadership. }\end{array}$ & $1.13 \pm 1.36$ & $1.93 \pm 1.22$ & $1.43 \pm 0.99$ & 0.059 & $2.67 \pm 0.58$ & $1.88 \pm 0.90$ & $2.40 \pm 0.55$ & 0.191 & $1.50 \pm 0.58$ & $2.20 \pm 1.23$ & $0.50 \pm 0.71$ & 0.140 \\
\hline
\end{tabular}

N.B: Total number $=168$.

$P$ - Value at $\leq 0.05$

Table (4): Correlation between items of professional practical model among the studied subject

\begin{tabular}{|c|c|c|c|c|c|c|c|c|c|c|c|c|c|c|c|c|}
\hline \multirow{2}{*}{$\begin{array}{c}\text { Professional } \\
\text { practical model } \\
\text { items }\end{array}$} & \multicolumn{2}{|c|}{ Steward-ship } & \multicolumn{2}{|c|}{ Teamwork. } & \multicolumn{2}{|c|}{$\begin{array}{c}\text { Primary care } \\
\text { team. }\end{array}$} & \multicolumn{2}{|c|}{$\begin{array}{l}\text { Professional } \\
\text { development. }\end{array}$} & \multicolumn{2}{|c|}{$\begin{array}{c}\text { Quality } \\
\text { outcomes. }\end{array}$} & \multicolumn{2}{|c|}{$\begin{array}{c}\text { Shared } \\
\text { governance. }\end{array}$} & \multicolumn{2}{|c|}{$\begin{array}{c}\text { Transformati } \\
\text { onal } \\
\text { leadership. }\end{array}$} & \multicolumn{2}{|c|}{ Total } \\
\hline & $\mathbf{R}$ & P-V & $\mathbf{R}$ & P-V & $\mathbf{R}$ & P-V & $\mathbf{R}$ & P-V & $\mathbf{r}$ & P-V & $\mathbf{r}$ & P-V & $\mathbf{r}$ & P-V & $\mathbf{r}$ & $\mathbf{P}-\mathbf{V}$ \\
\hline Stewardship. & ------ & $\begin{array}{ll}---- \\
\end{array}$ & 0.397 & $0.000 *$ & 0.469 & $0.000 *$ & 0.203 & $0.005^{*}$ & 0.410 & $0.000^{*}$ & 0.354 & $0.000^{*}$ & 0.226 & $0.003 *$ & 0.632 & $0.000^{*}$ \\
\hline Teamwork. & 0.397 & $0.000 *$ & ----- & $\begin{array}{ll}---- \\
\end{array}$ & 0.390 & $0.000 *$ & 0.099 & 0.202 & 0.441 & $0.000^{*}$ & 0.365 & $0.000^{*}$ & 0.196 & 0.011 & 0.586 & $0.000^{*}$ \\
\hline Primary care team. & 0.469 & $0.000 *$ & 0.390 & $0.000 *$ & $\begin{array}{ll}---- \\
\end{array}$ & $\begin{array}{ll}---- \\
\end{array}$ & 0.203 & $0.008 *$ & 0.462 & $0.000 *$ & 0.435 & $0.000^{*}$ & $.0 . .346$ & $0.000^{*}$ & 0.743 & $0.000 *$ \\
\hline Professional development. & 0.203 & $0.005 *$ & 0.099 & 0.202 & 0.203 & $0.008 *$ & $\begin{array}{ll}---- \\
\end{array}$ & ----- & 0.099 & 0.200 & 0.132 & 0.088 & 0.089 & 0.251 & 0.410 & $0.000 *$ \\
\hline Quality outcomes. & 0.410 & $0.000 *$ & 0.441 & $0.000 *$ & 0.462 & $0.000 *$ & 0.099 & 0.200 & ----- & $\begin{array}{ll}---- \\
\end{array}$ & 0.498 & 0.000* & $0 . .266$ & $0.001 *$ & 0.709 & 0.000* \\
\hline Shared governance. & 0.354 & $0.000 *$ & 0.365 & $0.000 *$ & 0.435 & $0.000 *$ & 0.132 & 0.088 & 0.498 & 0.000* & ----- & $\begin{array}{ll}---- \\
\end{array}$ & $0 . .283$ & $0.000^{*}$ & 0.770 & 0.000* \\
\hline $\begin{array}{l}\text { Transformational } \\
\text { Leadership. }\end{array}$ & 0.226 & $0.003 *$ & 0.196 & 0.011 & 0.346 & $0.000 *$ & 0.089 & 0.251 & 0.266 & $0.001 *$ & 0.283 & $0.000 *$ & ----- & ----- & 0.547 & $0.000 *$ \\
\hline Total & 0.632 & $0.000 *$ & 0.586 & $0.000^{*}$ & 0.743 & 0.000* & 0.410 & $0.000 *$ & 0.709 & 0.000* & 0.770 & 0.000* & $0 . .547$ & $0.000 *$ & & \\
\hline
\end{tabular}

N.B: Total number

Pearson correlation test 
Fig. (1): Correlation between items of professional practical model / work satisfaction as perceived by the studied Nurse Managers.

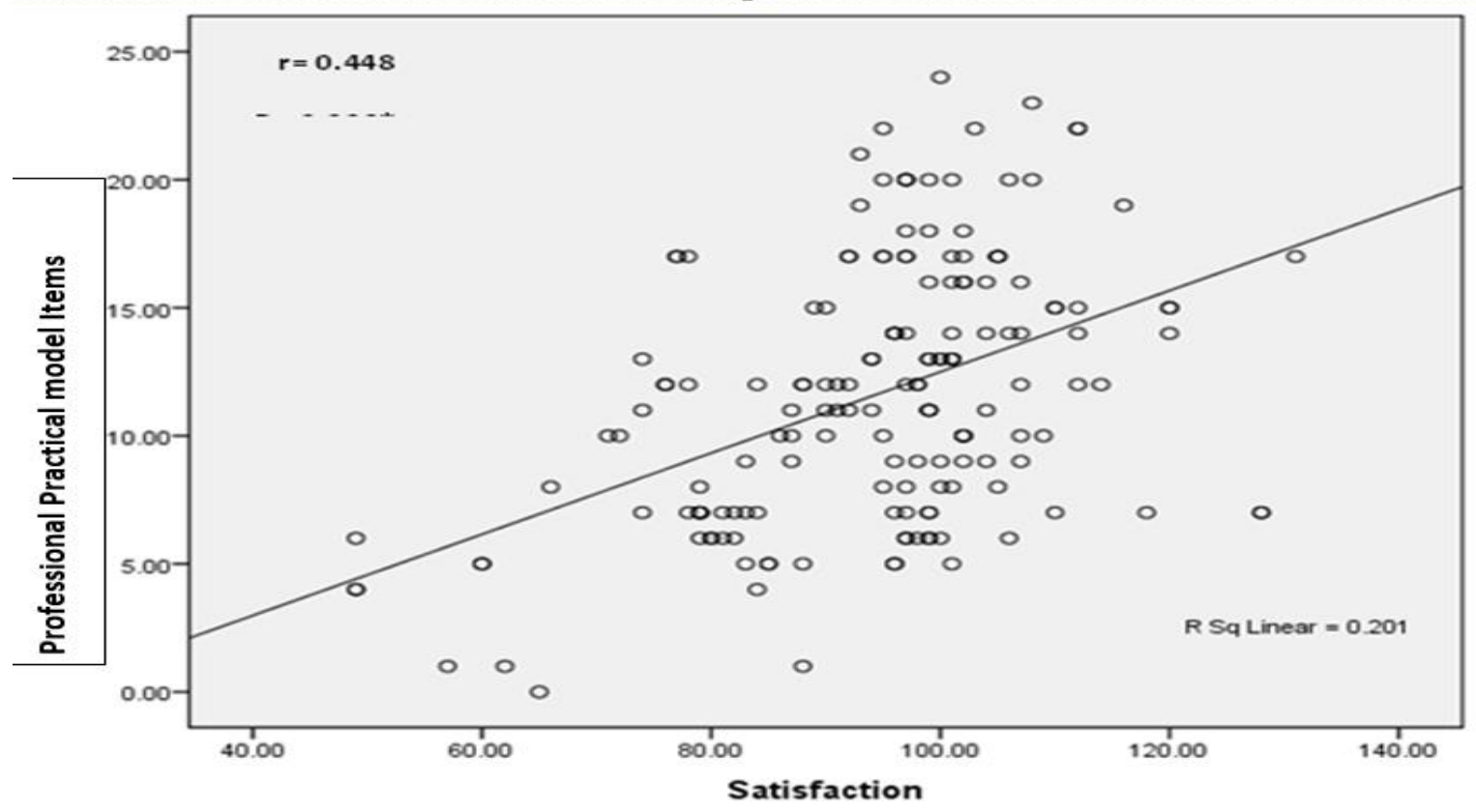

N.B: Total number (168)

Table (1): This table Illustrated that, the majority of study subject were females $\mathbf{( 9 5 . 8 \% )}$ ) and aged less than 35 years $\mathbf{( 5 1 . 2 \% )}$, having Bachelor degree on nursing science $\mathbf{( 7 3 . 8 \%}$ ), married $(\mathbf{8 0 . 4 \%})$ and have years of experience between $5-<10(\mathbf{3 3 . 4 \%})$.

Table (2): This table showed that, the highest mean score of items of professional practical model in El Rajhe hospital in the study subject Professional development, Shared governance, Primary care team, Quality outcomes, Transformational leadership and Stewardship $(3.06 \pm 0.84,2.84 \pm 2.05,2.34 \pm 1.29$, $2.19 \pm 1.00,2.03 \pm 0.86 \& 1.56 \pm 0.62)$. While the highest mean score of items Teamwork in Al Orman Hospital $(\mathbf{1 . 0 0} \pm \mathbf{0 . 7 3})$, followed by in El Rajhe hospital $(0.97 \pm \mathbf{0 . 8 2})$ and finally in main hospital $(0.35 \pm 0.60)$ and there were statistically significance differences among hospitals in the study in items Stewardship, Teamwork, Quality outcomes and Primary care team $\quad(* P \leq 0.000 *, 0.000 *, 0.000 * \&$ 0.0004*)

Table (3): This table depicted that, The highest mean scores founded as regard items of shared governance in all setting in the study subject were satisfied $(5.00 \pm 1.73,3.00 \pm 1.63 \& 2.38 \pm 1.41)$ respectively, followed by items of Professional development were dissatisfied in main hospital, followed by Al Orman Hospital $(3.04 \pm 1.36 \& 3.00 \pm$ 1.41). While in El Rajhe hospital the study subject were Natural about the same item $(3.21 \pm \mathbf{0 . 8 8})$.
There were statistically significance differences in the item of stewardship in all hospital in the study.

Table (4): This table represented that, there was a highly positive correlation between professional practical model item (quality outcome and shared governance $)(r=0.498 \& \quad P \leq 0.000 *)$. and highly positive correlation shared governance $(r=0.770 \& P$ $\leq \mathbf{0 . 0 0 0} *)$, followed by primary care team $(r=0.743 \&$ $\left.\mathbf{P} \leq \mathbf{0 . 0 0 0}^{*}\right)$, and finally quality outcome $(\mathbf{r}=\mathbf{0 . 7 0 9 \&}$ $\mathbf{P} \leq \mathbf{0 . 0 0 0 *})$. And there are statistical significant differences among all items.

Fig. (1): Showed that, there was a highly positive correlation between professional practical model and work satisfaction items, $((\mathbf{r}=\mathbf{0 . 4 4 8} \& \mathbf{P} \leq \mathbf{0 . 0 0 0} *)$.

\section{Discussion:}

A professional practice model describes how registered nurses practice, collaborate, communicate, and develop professionally to provide the highestquality care for those served by the organization. The present study was conducted with the aim to assess Nurse Managers perception regarding professional practical model at Assiut University Hospitals, and identify effects of professional practical model on Nurse Managers work satisfaction.

The highest mean score of items of professional practical model in El Rajhe hospital in the study subject Professional development, Shared governance, Primary care team, Quality outcomes, Transformational leadership and Stewardship. While 
the highest mean score of items Teamwork in Al Orman Hospital, followed by in El Rajhe hospital) and finally in main hospital, this resulted statistically significance differences among hospitals in the study in items Stewardship, Teamwork, Quality outcomes and Primary care team.

The highest mean scores founded as regard items of shared governance in all setting in the study subject were satisfied, followed by items of Professional development were dissatisfied in main hospital, followed by Al Orman Hospital. While in El Rajhe hospital the study subject was Natural about the same item. There were statistically significance differences in the item of stewardship in all hospital in the study. This finding consistent with Karen, et al. (2012) study where he represented that, the professional practice model may have increased awareness of the components of job satisfaction that were not being met. Accordingly, the nurses may have gotten more educated about the possible requirements their areas. On the other hand, Murphy et al. (2017) referred in his study that The professional practice model guides nursing personnel to consider the depth and complexity of the nursing interaction; it guides us to give our particular nursing care to patients and record and measure its adequacy while additionally embraced a focal job in the shared act of the multidisciplinary team. Simultaneously, somehow or another executing the professional practice model can appear to be a major change way nurses' practice; however this change can bring advantages, for example, expanding our power over our training and giving us more opportunity to go through with patients. Also Lorie, et al (2017) revealed that the accompanying topics arose in professional model attunement, commonality/knowing the patient, taking care of business, patient results, consistency and congruity of care, self-governance/stepping up to the plate, nurture rewards: satisfaction and responsibility, empowerment/input, and Facilitating frameworks: communication, support and assignment.

From the findings of the present study, it is appeared that there is a highly positive correlation between professional practical model and work satisfaction items. This finding consistent with Persefoni, et al (2019) who reported that there was a positive correlation between nursing Professional Practical Model and work satisfaction. In any case, further researches are expected to decide and quantify the level of such correlations. The information acquired from future researches that bring about the improvement of hypothetical ideas and speculations will add to the information accessible in the space of nursing administration. Professional Practice Environments show a guarantee to security in the work environment, prompting generally work satisfaction. At the point when health providers are satisfied with their positions, paces of truancy and turnover decline, staff assurance and profitability increment, and work execution overall improves. Safe patient consideration is straightforwardly and positively contributed to the quality of nurses' work environments. On the other hand, Lois, M., \& Maria, R. (2015) reported that Positive relationships were seen between the inception of a Professional Practical Model and resulting nurses' view of quality of care, nurse cooperation, decision making, autonomy, job enjoyment, and patient satisfaction.

\section{Conclusion:}

Based on the results of the present study, the following conclusions: statistically significance differences among hospitals in the study in items Stewardship, Teamwork, Quality outcomes and Primary care team., There was a highly positive correlation between professional practical model and work satisfaction items.

\section{Recommendations:}

1. The researcher given all Nurse Managers at Assiut University Hospital Pursuer about Professional Practical model that included the important of this model for applied in their organization.

2. The board of director should give the Nurse Managers opportunities to their area of responsibility participate in goals setting and degree of autonomy with regard to increase their commitment toward goal achievement.

3. Provide in service training workshop for different nurse managers about professional practical model.

4. Design Professional Practice Model in alignment with organizational context can indeed impact nurse and patient outcomes in a community health system.

5. Using PPMs and primary nursing as effective frameworks to positively impact nursing and patient outcomes in all units.

6. Nurse Managers and leaders must recognize that job satisfaction consists of many dimensions, and each of these dimensions is important to nurse retention.

7. Implementation of a professional practice model may heighten awareness of the missing components within a practice environment and lead to decreased overall satisfaction.

8. A broader understanding of characteristics associated with increased satisfaction may aid in development of organizational change necessary to retain and attract nurses. 
References

- Ahmed, H. (2013): Shared governance and it's effects on Head Nurses Work Satisfaction, Master thesis's

- Barden A.M., Griffin M.T., Donahue, M. \& Fitzpatrick J.J. (2011): Professional practical model and empowerment in registered nurses working in a hospital setting. Nursing Administration Quarterly, 35(3): by W.B. Saunders Inc, Pp. 212-218. Cited by: Hess, R. (2011): Citations related to the development or use of the Index of Professional Nursing Governance, Professional practical model Journal, 35(3): by W.B. Saunders Inc, Pp.1-7.

- Buchan, J., Aiken LH, Buchan J, Ball J, \& Rafferty AM. (2018): Transformative impact of Magnet designation: England case study. J Clin Nurs; 17(24):3330-7.

- Edmonstone, J. (2000): Empowerment in the National Health Service: does professional practical model offer a way forward? Journal of Nursing Management. 8, (1), by W.B. Saunders Inc, Pp 259-264.

- Goeddeke, A. (2010): Professional practical model in Nursing: Case Studies in Collaborative DecisionMaking.

- Hawkins L., Catherine M., Christine C., \& Judy W. (2011): Professional Practice in Human Service Organizations a practical guide for human service workers

- Hazel, C., Pierce, L., \& Lorraine C. (2006): Nursing Management; Effect of a professional practice model on autonomy, job satisfaction and turnover

- Krajewski, R., Anne M., Karen, B. , Claire, A., Suzanne, S., Marlene, G. \& Sullivan, S. (2012): Professional practical model: Early Payoffs from Leadership and Staff Engagement, Nurse Leader Journal,5,(5), October, by Mosby, Inc. Pp 38-42, 54

- Karen, M., Mary, Q., Moreen, D., \& Joyce, J. (2012): Registered nurse job satisfaction and satisfaction with the professional practice model

- Kennerly, S. (2000): Perceived worker autonomy. Journal of Nursing Administration, 30(12), by W.B. Saunders Inc. Pp. 611-617. Cited by: Anthony, M. (2004): "Professional practical model Models: The Theory, Practice, and Evidence". Online Journal of Issues in Nursing. 9 (1) January 31, Manuscript 4. by Main Menu Categories, ANA Marketplace, ANA Periodicals\& OJIN, Pp. 32-41.

- Lois, M., \& Maria, R. (2015): Predictability of a Professional Practice Model to Affect Nurse and Patient Outcomes

- Lori，H., Jane，R., Julie，A., Lawrence，M., Sharon, W., Heather, K., Laschinger, A. Joy B. \& Karen O. (2017): Nurses' perceptions of the impact of a renal nursing professional practice model on nursing outcomes, characteristics of practice environments and empowerment.

- Main Line Health (2020): Professional development activities and embrace evidence-based practice. https://diversitynursing.com.

- Meehan, L (2020): Professional Practice Model, Careful Nursinghttps://www.carefulnursing.

- Megginson, S (2017): government ownership is related to reduce firm liquidity.

- Michael, W. (2012): Effective Teamwork: Practical Lessons from Organizational Research. Wiley-Blackwell. ISBN 978-0-470-97498-8.

- Murphy S, Mc Mullin R, Brennan S \& Meehan TC (2017): Exploring implementation of the Careful Nursing Philosophy and Professional Practice Model@ in hospital-based practice. Journal of Nursing Management.

- Persefoni, L., Anastasios, M., Nicos M.,\& Evridiki, P. (2019): Nurses perceptions of their professional practice environment in relation to job satisfaction: a review of quantitative studies

- Roger, C. (2015): Examining teamwork and leadership in the fields of public administration, leadership, and management". Team Performance Management. 21 (3/4): 199-216. Doi: 10.1108/TPM-07-2014-0037.

- Setting Goal institution (2019): The Path to Work Satisfaction, Books \& Journals, Health Administration Press journal, by American College of Healthcare Executives. Available from: http://www.work-satisfaction.html.

- Slatyer, S., Coventry, L., Twigg, D. \& David, S. (2016): Professional practice models for nursing: a review of the literature and synthesis of key components. Journal of Nursing Management, 24, 139-150.

- Stanford Health Care (2000): Learn brings together leading-edge technology, innovative research, and world-renowned Washington Hospital | Stanford Health Carehttps://stanfordhealthcare.org > clinics

- Susan, M. (2011): Employee Satisfaction Definition of Employee Satisfaction, by A part of The New York Times Inc. available from: www. Employee Satisfaction - Definition of Employee Satisfaction.mht

- Wikipedia, (2019): Professional Practical Model and its effect work satisfaction 